\title{
Performance of Integrated Fixed-Film Activated Sludge (IFAS) under Variable Organic Load
}

\author{
Abdelsalam Elawwad, Omar Abdelkarim, Minerva Edward \\ Environmental Engineering Dept., Faculty of Engineering, Cairo University \\ El-Gamaa St., 12613 Giza, Egypt \\ elawwad@cu.edu.eg, omar.abdelkarim@hotmail.com, minervaav@cu.edu.eg
}

\begin{abstract}
In this research, a pilot plant was constructed and operated using the Integrated Fixed Film Activated Sludge (IFAS) to study its performance for municipal wastewater treatment. The experimental work was conducted at Zenien WWTP under variable organic loads. The system was operated under ambient temperature between 16 and $28{ }^{\circ} \mathrm{C}$. The media used in the pilot plant was of the type (FAB) with a specific surface area of $400 \mathrm{~m}^{2} / \mathrm{m}^{3}$ and occupied $50 \%$ of the reactor's volume. The solid retention time (SRT) was 15 days during the start-up stage, then reduced to 10 days for the rest of the experiments, $\mathrm{pH}$ was $(6.2-7.8)$, the flow rate was $(3.61 \mathrm{~L} / \mathrm{hr})$, hydraulic retention time (HRT) was around 6 hrs over the whole experiment. The pilot plant was operated in stages each with a different organic load and lasted for about 60 days. The pilot plant proved its efficiency in wastewater treatment using IFAS system. Under low organic load, the BOD, COD and TSS removal reached 90\%, 88\% and 94.6\% respectively. Under medium organic load, the BOD, COD and TSS removal reached $93 \%, 87 \%$, and $87.8 \%$, respectively.
\end{abstract}

Keywords: IFAS, wastewater, variable load, activated sludge.

\section{Introduction}

Discharge of untreated sewage to the environment is one of the major environmental problems [1]. Many developing areas suffer from a lack of appropriate water and sanitation services in many countries [2]. Improvement of existing wastewater treatment plants is necessary for several reasons: population growth within the service area, adding new service area to the plant, and improvement of the effluent of the WWTP for environmental requirements. Enhancement of the WWTP for these reasons can be achieved by increasing the plant's efficiency. Thus, various methods were developed to improve the existing WWTP by increasing both its efficiency and its capacity.

Integrated Fixed Film Activated Sludge System (IFAS) is a hybrid system considered as one of the solutions that can enable us to enhance the existing wastewater treatment plants [3]. It combines both the suspended and attached growth in the same reactor. Its concept relies upon adding media to the activated sludge process allowing progressively microbial development. Microorganisms form a biofilm on the media, thus enhancing the performance of the activated sludge system, and increasing the treatment capacity with no need for treatment units. In addition, it is viewed as one of the minor cost answers for increasing the capacity of a plant and upgrading the nature of the treated effluent. IFAS increase activated sludge plant capacity, with practically zero included tankage, as a result of the extra fixed biomass. This extra biomass serves to balance out the expanding organic loading. Along these lines, the system can suit increasingly organic loading and offer higher treatment quality. There are two types of media used to fix the biomass in the activated sludge tank. The type of media relies upon the kind of submergence: Dispersed Media is free plastic pieces tossed in the tank, while Fixed Media will be media fixed in an edge inside the aeration tank [4]. Dispersed media has a bigger surface area per unit volume than the fixed media, therefore, it gives a bigger supporting surface to the biomass and more substrate could be treated. Dispersed media has the advantage that it is self-cleaning, and requires no backwashing provided that vigorous agitation is allowed. Then again, dispersed media has a few weaknesses. One of which is that dispersed media may encounter washout to the final clarifier which can be solved by utilizing a screen at the outlet of the aeration tanks [5]. The percentage of media fill percentage inside the aeration tank can reach $35-65 \%$ of the reactor's volume [6]. The most broadly utilized media material is the high-density polyethylene HDPE and the high-density polypropylene HDPP. These materials are profoundly inert, of reasonable specific gravity and might be shaped effortlessly. One of the advantages of IFAS is that biomass population is 
not exposed to biomass washouts during hydraulic surges and shocks where the biomass is fixed set up and goes about as a "re-seeding" to get the system to come back to typical activity.

The objective of this research is to evaluate the performance of the IFAS system constructed and operated in Zenein WWTP under several operating conditions, before adding media and at 50\% media fill percentage of the reactor's volume at different organic loads.

\section{Materials and methods}

\section{Experimental Model set-up}

The pilot plant used in this research was operated in Zeinein WWTP, Giza Governorate, Egypt. It was placed next to the primary sedimentation tanks. It has consisted of three separate tanks: feeding tank, aeration tank and final sedimentation tank. The primary treated wastewater is conveyed to the feeding tank by a submersible pump which draws water through a PP pipe of 1-inch diameter. The feeding tank height ensures the necessary head for feeding the aeration tank at a constant flow. The feeding tank has a cylindrical shape and a 500-liter capacity.

The aeration tank is the main biological treatment process reactor where primary settled wastewater is placed with the active biomass. The tank is square in shape with $0.75 \times 0.40 \times 0.42 \mathrm{~m}$ total depth, and an active depth of $0.38 \mathrm{~m}$. Two parallel perforated pipes are placed at the bottom of the aeration tank which works as air diffusers (coarse bubbles). Air is delivered to the aeration tank from the air blowers in Zenein WWTP which blow air continuously over 24 hours through a 1.5-inch PP pipe to the pilot plant. Air flows to the pilot plant is controlled to the aeration tank by a sluice valve (on/off) and flow control valve. Air serves to keep the liquid in the tank mixed and provides an adequate amount of oxygen to sustain microorganisms.

The final sedimentation tank consists of two parts: the first part is a parallelogram of dimensions $0.65 \times 0.50 \times 0.50 \mathrm{~m}$. A sludge hopper is constructed at its bottom for sludge withdrawal. The second part is a pyramid shape with an upper crosssectional area of $0.5 \times 0.5 \mathrm{~m}$ and a bottom cross-sectional area of $0.15 \times 0.15 \mathrm{~m}$. The height of the hopper is $0.3 \mathrm{~m}$. Sludge is withdrawn from the bottom of the clarifier by a pump that lifts it back to the aeration tank as shown in Figure (1).

Sludge is returned to the head of the aeration tank to re-seed the new sewage entering the tank. Return activated sludge supplied to the aeration tank is used to increase the MLSS once it drops under the designated value. The sludge pump is operated for one minute every hour and a half. Return sludge is returned by the RAS pump through a plastic pipe of 1.0-inch diameter to the inlet of the aeration tank as shown in Figure (1). The excess sludge is removed 2 times/day by a 1-inch plastic pipe. The flow was set at 450 1/day on average throughout the whole experiments which would result in HRT of about 6 hours in the aeration tank.

Influent and effluent samples were collected two times a week and analyzed for COD, BOD 5 , TSS, and VSS, while sludge samples were analyzed for mixed liquor suspended solids (MLSS), Mixed Liquor volatile solids (MLVSS), Settling Tests (SV30) and SVI.

Analytical methods used were according to "American standards methods for the examination of water and wastewater". (APHA, 1995), and the analysis of the samples was conducted at Zenein WWTP laboratory, Giza, Egypt, and Accurate Analysis Center, Faculty of Science, Cairo University.

\section{Support Media}

The selected media was plastic pieces that will be referred to as "FAB" and is locally manufactured. It has been used with a filling rate of $50 \%$ of tank volume as shown in Figure (2). The technical specification of FAB media are as follows: effective surface area $400 \mathrm{~m}^{2} / \mathrm{m}^{3}$, height $15 \mathrm{~mm}$, diameter $20 \mathrm{~mm}$, weight $0.37 \mathrm{~kg} / \mathrm{m}^{2}$, specific gravity $0.9-0.95 \mathrm{gm} / \mathrm{cm}^{3}$.

\section{Start-up stage}

This stage was conducted under the following operating conditions: SRT $=15$ days, no media was added, duration of this stage 60 days, average influent $\mathrm{pH}=7.1$, average $\mathrm{pH}$ effluent $=8.0$, and average temperature $=26.1^{\circ} \mathrm{C}$. 


\section{Low organic load stage}

This stage was carried under low organic load, synthetic wastewater was mixed with the real wastewater to reach the specified organic load COD of $(350-400) \mathrm{mg} / \mathrm{l}$, SRT $=15$ days, percentage of media fill percentage $50 \%$, duration of this stage 60 days, average influent $\mathrm{pH} 7.4$, average effluent $\mathrm{pH} 7.4$, and average temperature $23{ }^{\circ} \mathrm{C}$.

\section{Medium organic load stage}

This stage was carried under medium organic load synthetic wastewater to be mixed with the real wastewater to reach the specified organic load COD of (550-600) $\mathrm{mg} / \mathrm{l}$. SRT $=15$ days, percentage of media fill percentage $50 \%$, duration of this stage 60 days, avg. $\mathrm{pH}$ (in) 7.4, avg. $\mathrm{pH}$ (out) 7.4, Avg. Temperature $19.3^{\circ} \mathrm{C}$.

\section{Measured parameters}

Samples were taken twice a week to analyze different parameters out of which are the BOD, COD, TSS, VSS, $\mathrm{NH}_{3}-\mathrm{N}$, $\mathrm{NO}_{3}$, SV30, DO, $\mathrm{pH}$ and temperature. $\mathrm{pH}$ was measured using $\mathrm{pH}$ meter model (WTW). Spectrophotometer model HACH DR400 was used to measuring the concentration of Nitrates, Nitrite, and COD. The removal percentage is calculated using Eq.(1), organic loading was calculated using equation Eq (2), and removal rate was calculated using Eq (3)

$$
\begin{gathered}
\% \text { Removal }=\frac{\text { Influent Parameter }- \text { Effluent Parameter }}{\text { Influent Parameter }} \times 100 \\
\text { Organic Load }=\frac{\text { COD } x Q}{V} \\
\text { Removal Rate }=\text { flow } *\left(\frac{\text { Influent Parameter }- \text { Effluent Parameter }}{\frac{1000}{115} / 1000}\right)
\end{gathered}
$$

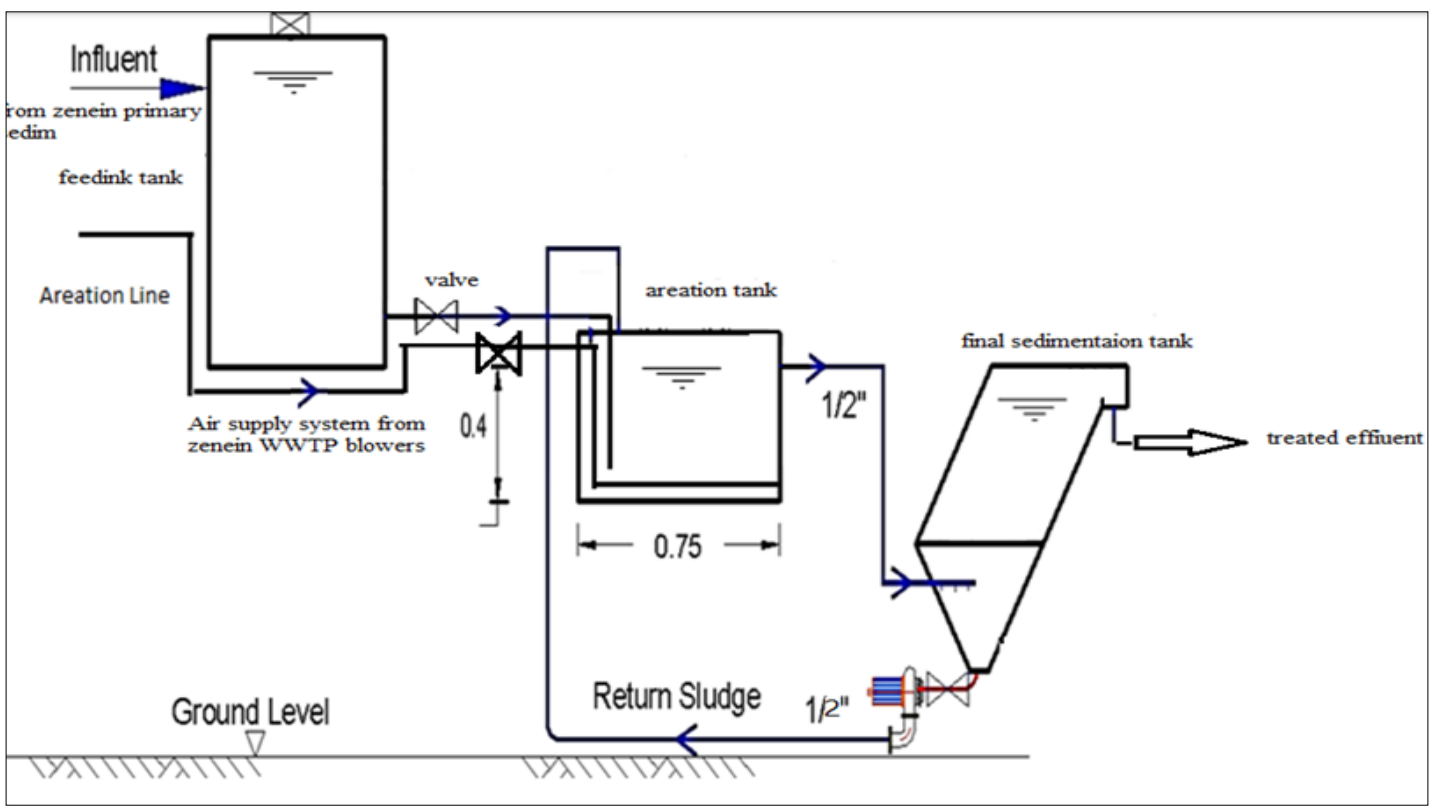

Fig. 1: Process flow diagram of the pilot plant 

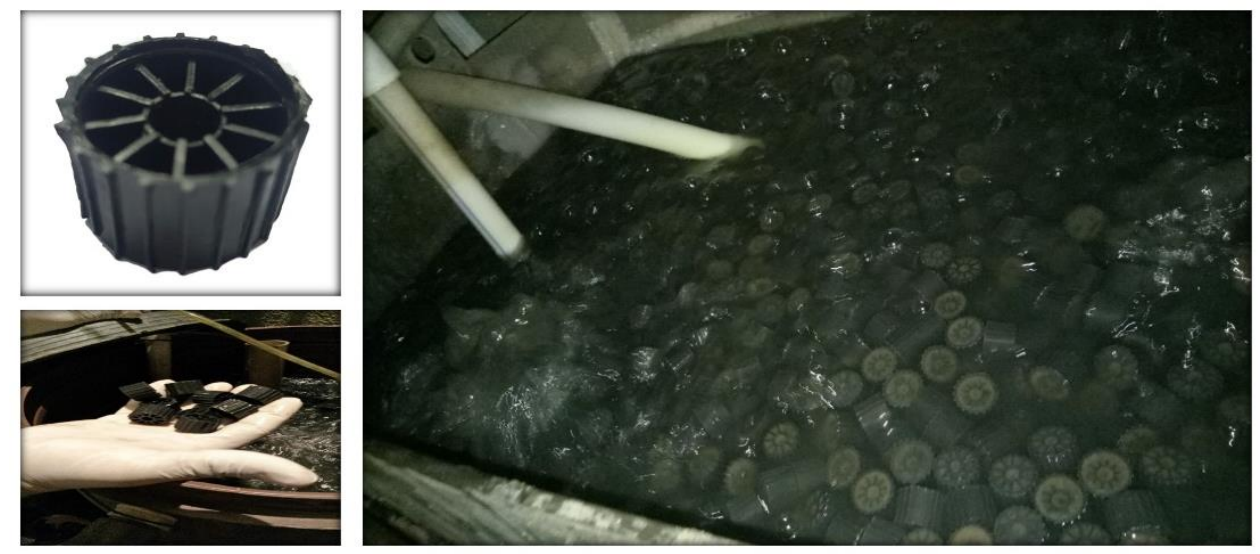

Fig. 2: Media used in the system with $50 \%$ fill percentage in the tank.

\section{Results and Discussions}

Figure (3) shows BOD removal efficiency, in start-up stage, the removal efficiency was low at the beginning as bacteria needed time to be adapted to the new medium. After two weeks of the start-up stage, the removal efficiency ranged between $62-87 \%$. In the low organic load stage, the removal rate gradually increased from 85\% to $92 \%$, as for the medium organic load stage, removal efficiency reached $93 \%$. This indicates that the bacteria have adapted to the medium and are capable of removal of the organics under the variable organic loads.

Figure (4) shows COD efficiency. Number of the samples taken in each stage was was 17 samples. During the startup stage, the removal efficiency was low at the beginning of the stage as bacteria need time to adapt to the new medium. Then, after two weeks of the start-up stage, the removal efficiency ranged between $75 \%$ and $88 \%$ ). In the low organic load stage, the removal rate gradually increased from $82 \%$ to $92 \%$, as for the medium organic load stage, removal efficiency decreased to $87 \%$. This indicates that the best stage in removing COD is the low organic load stage. The pilot plant was capable of removing the COD under the variable organic loads.

Figure (5) shows TSS efficiency in all stages of pilot reactor operation: the start-up stage, low load stage and medium organic load stage. In each of these stages, the number of samples taken was 17 samples. During the start-up stage, the removal efficiency ranged between $40 \%$ and $80 \%$. During the low organic load stage, the removal rate gradually increased from $80 \%$ to $94 \%$, while for the medium organic load stage, removal efficiency reached $87.8 \%$. This indicates that the best stage regarding TSS removal is the low organic load stage. The pilot plant was capable of TSS removal under variable organic loads.

In this research, the results were found close to the literature. The system showed high COD and BOD removal efficiencies which is due to favourable conditions especially temperature suitable for the growth of bacteria. Elhattab (2011) [7] used IFAS system and reached a COD removal of $73.7 \%$, BOD removal of $73.8 \%$ at SRT 15 days and HRT 10 hrs. Azimi et al. (2007) [8] reached a COD removal of 90\% at SRT 10 days and HRT of only 1.3 hrs. Di Trapani, et al. (2013) [9] reached a COD removal of $87 \%$, BOD removal of $85 \%$ at SRT 8.5 days and HRT 3.4 hrs. Future work should concentrate on the modelling of IFAS system. Modelling is useful for operational decision-making, as well as for upgrading the existing WWTPs [10]. 

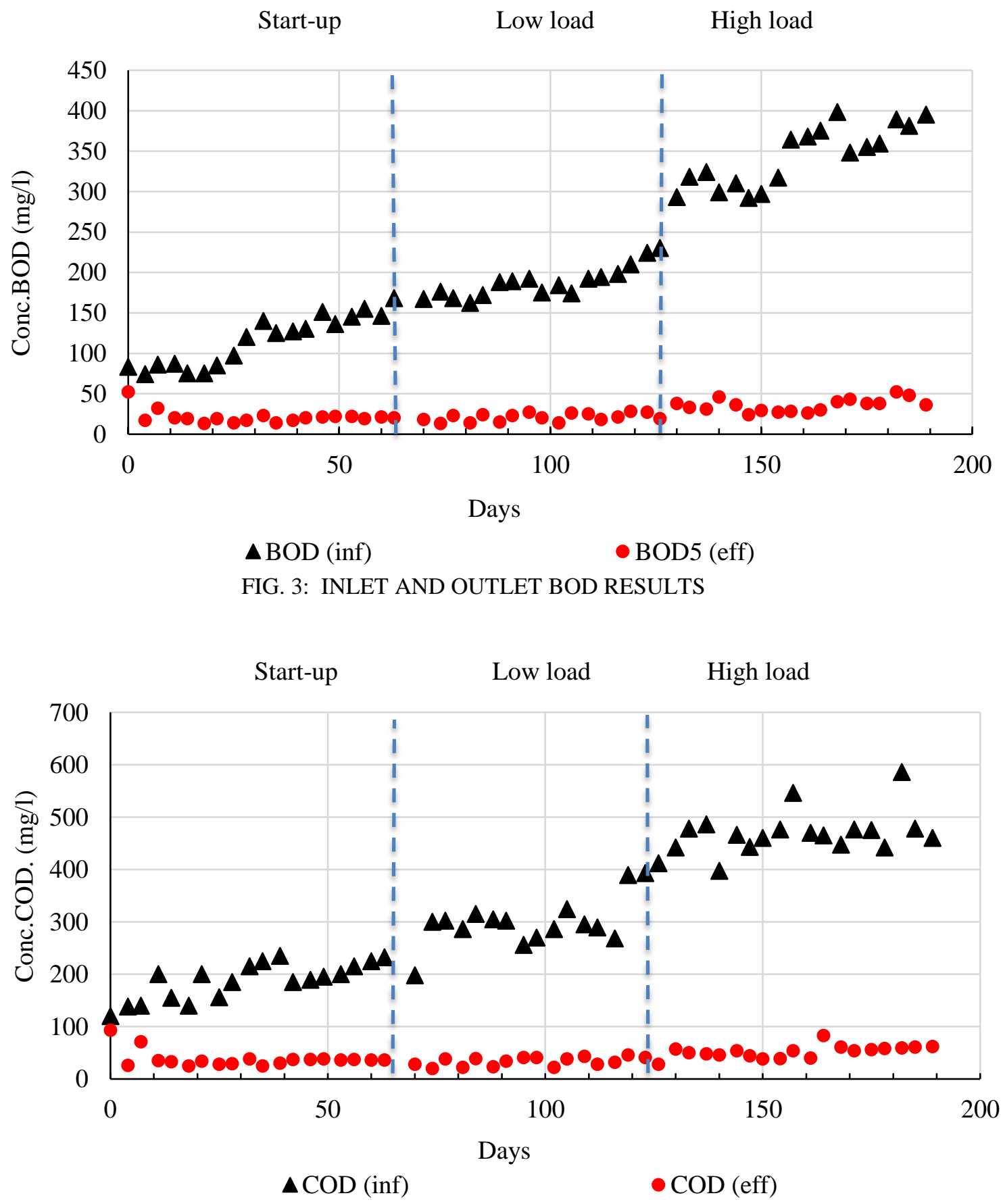

FIG. 2: : INLET AND OUTLET COD RESULTS 


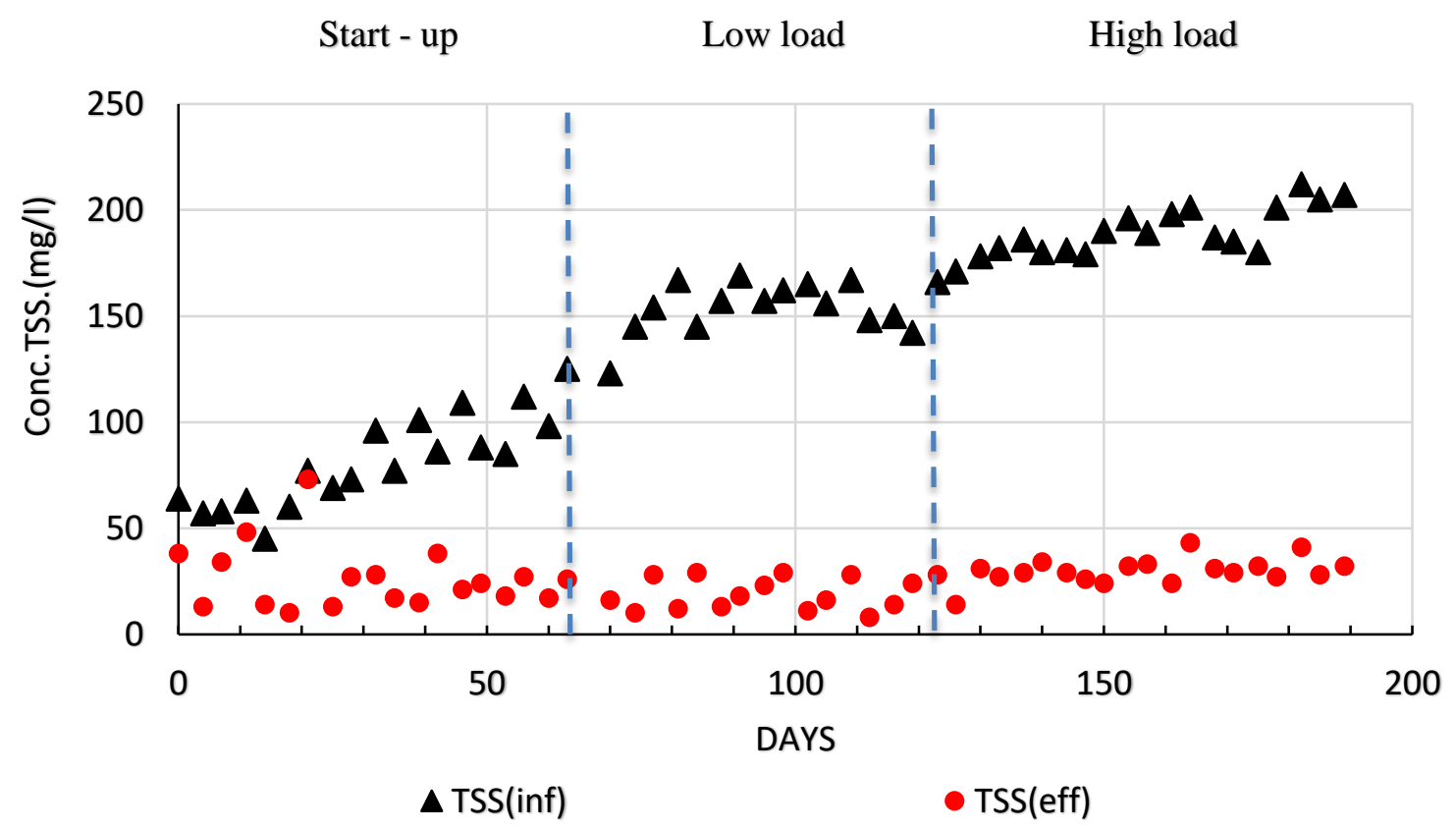

FIG. 2: INFLUENT AND EFFLUENT TSS RESULTS

\section{Conclusion}

The pilot plant proved its efficiency in municipal wastewater treatment using IFAS system under variable operating conditions of low organic load (350-400) mg/l of COD, and medium organic load (550-600 mg/l) of COD. Using IFAS could be a cost-effective option for upgrading existing activated sludge systems especially those that suffer from a lack of lands. Moreover, IFAS can help existing WWTPs that are originally designed for organic removal only to introduce ammonia removal. The disposal of untreated ammonium wastewater in water bodies has the harmful effect of free ammonia (FA) on aquatic life [11].

\section{References}

[1] Elawwad, A., Hazem, M. "Minimization of sludge production in an integrated UASB-continuous flow sequencing batch reactor system," Desalination and Water Treatment, vol. 91, pp. 206-213, 2017.

[2] Elawwad, A., Rageb, M., Abdel-Halim, H., "An economical, environmental and social comparison between vacuum and gravity sewers in decentralized sanitation systems, with Egypt as a case study," Journal of Water Sanitation and Hygiene for Development, vol. 5, no. 4, pp. 614-619, 2015.

[3] Waqas, S., Bilad, M.R., Man, Z., Wibisono, Y., Jaafar, J., Mahlia, T.M.I., Khan, A.L., Aslam, M., Recent progress in integrated fixed-film activated sludge process for wastewater treatment: A review, Journal of Environmental Management, Vol. 268, 2020.

[4] Jones, R. M., Sen, D., and Lambert, R., "Full scale evaluation of nitrification performance in an integrated fixed film activated sludge process.” Water Science and Technology, Vol. 38 No.1, pp. 71-78, 1998.

[5] Aygun, A., Nas, B., and Berktay, A., "Influence of high organic loading rates on COD removal and sludge production in moving bed biofilm reactor." Environmental Engineering Science, 25(9), 1311-1316, 2008.

[6] Hait, S., and Mazumder, D., "Scope of improvement of treatment capacity of activated sludge process by hybrid modification." Journal of Environmental Engineering and Science, 7(2), 147-158, 2008.

[7] El Hattab, N.A., Halim, H.A., Matta, Minerva, "Performance of IFAS using dispersed media in organic matter removal and nitrification of wastewater", Journal of Engineering and Applied Science. 58, pp. 459-477, 2011. 
[8] Azimi, A. A., Hooshyari, B., Mehrdadi, N., and Bidhendi, G. N., "Enhanced COD and nutrient removal efficiency in a hybrid integrated fixed film activated sludge process". Iranian Journal of Science and Technology, 31(B5), 523, 2007.

[9] Di Trapani, D., Christensson, M., Torregrossa, M., Viviani, G., and Ødegaard, H., "Performance of a hybrid activated sludge/biofilm process for wastewater treatment in a cold climate region: influence of operating conditions". Biochemical Engineering Journal, 77, 214-219, 2013.

[10] Elawwad, A., Naguib, A., Abdel-halim, H., "Modeling of phenol and cyanide removal in a full-scale coke-oven wastewater treatment plant", Desalin. Water Treat., 57 (52), pp. 25181-25193, 2016.

[11] Elawwad, A., "Optimized biological nitrogen removal of high-strength ammonium wastewater by activated sludge modelling," Journal of Water Reuse and Desalination, vol. 8, no. 3, pp. 393-403, 2018. 